\title{
Conferência Realizada na Escola Superior de Guerra em 19-7-66
}

\author{
José de Almeida Rios
}

\begin{abstract}
OPINIÃO PỨBLICA E O ESTADO MODERNO
\end{abstract}
\section{CONCEITO}

M um grupo social, podendo ser modificada, ampliada, distorcida, encaminhada e reformada. Embora a área em que atua a opinião pública seja pelo volume ilimitável e mais extensa do que aquela das multidões, estas podem ser, por identidade, de motivos, um precipitado segmento daquela. $O$ que se convencionou chamar de opinião pública podem ser agrupamentos tomando atitudes por motivações identificadas com o pensamento do grupo em causa.

No processo ligado às multidões, elas refletem um estado transitório ou que perdura enquanto prevalecem os motivos ocasionais que resultaram no agrupamento formativo de opinião.

No caso de opinião durável, como aquela do povo, Dicey a define como «um conjunto de crenças, de concepções, de concessões, de sentimentos, de princípios aceitos ou de prejuízos fortemente arraigados» (A. V. DiRCEY - Le Droit et l'Opinion Publique en Anglaterre).

A tradição pressupõe um lastro de caráter que estratifica atitudes e procedimentos, afirma hábitos mentais e uniformiza o modo de sentir, pensar e agir de tôda uma sociedade. Esta se pode classificar como opinião estática ou de povo e a outra, dinâmica, mais acessivel a modificações e transformações e trabalhada fàcilmente pelos métodos modernos de técnica de propaganda.

É muita formalidade dizermos hoje que a opinião pública é o ingrediente da democracia. Na sua caracterização dinâmica dentro do quadro do processo de evolução social e especialmente política com a extrema facilidade sincrética criada pelos modernos 
meios de comunicação e de transportes, são incríveis as várias motivações que podem impressionar a opinião pública dinâmica, mesmo contra a si mesma e os interêsses da nacionalidade. A fase tremenda por que passam os países com desenvolvimento retardado, exigindo o acondicionamento de determinações técnicas com imposições politicas, diminui muito a importância da opinião pública dinâmica como fôrça consciente de poder. Aliás, a democracia não é sistema nem regime de govêrno e sim filosofia de vida de relações. Qualquer tipo de govêrno é passivel de poder cumprir os postulados de uma verdadeira democracia.

Uma opinião pode ser uma crença baseada em uma evidência limitada, estando sujeita a revisões provocadas por motivações as mais variadas. A própria mudança do caráter nacional pode levar a uma reformulação de opinião estática ou de povo. O caráter nacional ou de grupos influenciados pelas intromissões e transmissões culturais pode ser considerado como um fundamento de significação para a atitude social que chegue até a uma decisão ou julgamento. Sendo, segundo Riesman, o caráter nacional um produto de formas sociais, cuja estrutura poderá ser definida como uma organização mais ou menos permanente, social e històricamente condicionada, das tendências e satisfações individuais, fornece êle uma substância sólida de fundamentação de opinião pública. A evolução, as aculturações e as condições do meio, aliadas aos estágios educacionais sucessivos, afirmam e firmam novos propósitos, onde a opinião estática ou de povo vai, aos poucos, cedendo aos reclamos, motivações e ação da vida moderna da civilização. As intromissões e transmissões de cultura, acontecimentos sociais marcantes, eventos internacionais, condições econômicas e uma gama enorme de fatôres que alteram o sentido da personalidade podem conduzir à mudança de caráter e a tornar o campo mais fácil de transformações no que respeita à mudança de atitudes, tônica da opinião onde já encontramos o «juízo de valor» e a decisão.

Em verdade há profundo entrosamento entre indivíduo e coletividade. A influência tradicional, impregnada no indivíduo, transcende da própria personalidade para atingir as instituições. Os traços individuais determinam as instituições e estas, por sua vez, formulam o caráter. Assim, como é óbvio, as pesquisas de caráter têm que ser periódicas havendo uma forma histórica para avaliar o sentido da evolução. Antes, assim, de chegarmos a caracterizar a atitude ou predisposição para um «juizo de valor», formando o terreno onde se passa a decisão como ação última de opinião coletiva, se estabelece um processo de ampliação, partido de uma sintonia de sentimentos de classe e de grupos, tendendo a uma homogeneização da predisposição. 
As atitudes são avaliativas, dado que levam a comportamentos característicos. Elas são predisposições aprendidas e duradouras. Elas influenciam a percepção e a reação emocional. Fatos e acontecimentos refletem predisposições e reações com rumos incertos nos comportamentos. Os processos psico-sociais são sempre produtos secundários dos processos sociais. Os processos psicosociais são, por sua vez, freqüentemente absorvidos, capturados ou causados por fenômenos sócio-culturais, servindo mesmo para uma integração mais vasta no campo social considerado.

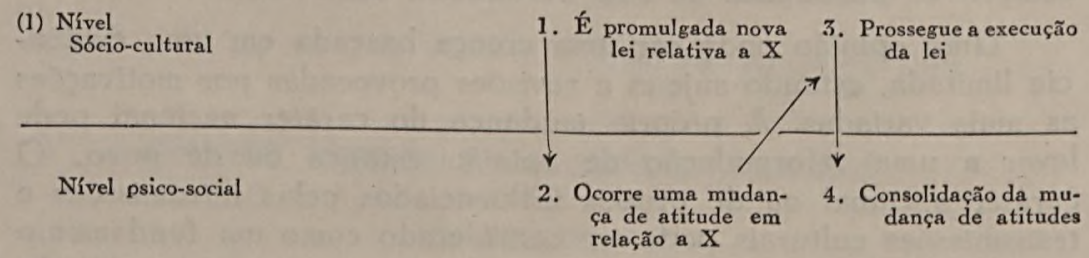

(2)

1. a) Oportunidade para crescente produtividade ou modernização

(W.Lambert)

(págs. 158-160)

b) a presença de valôres de independência ou uma mudança nos valôres ou alguma mudança "es-
trutural"

Eventos e processos s 6 - $\gamma$

- cio-culturais.

2. Mudança para o

treino precoce $\mathrm{de}$

independência nas crianças

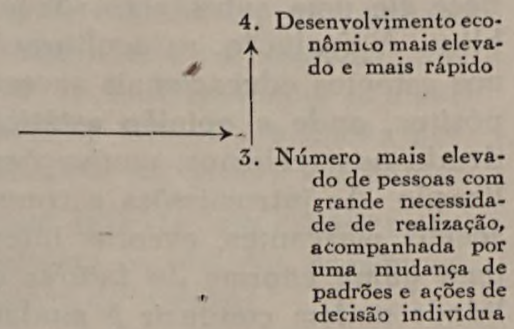

Os fatôres e motivações sociais que atingem ou causam impacto na mente humana e a levam a estabelecer associação de idéias e de pensamentos coletivos, procurando sincronismo de interêsses, formam os núcleos iniciais de opinião pública com ampliações imprevisiveis.

\section{DINAMMICA}

Em uma projeção estrutural, a opinião, dentro da ebulição de sua instabilidade conjuntural, vai, gradativamente, estabelecendo uma relativa estabilização obediente a uma certa padronagem construída por um processo sincrético entre a forma estática tradicional e a dinâmica. A primeira que denominamos «opinião do povo», calcada nos fundamentos formadores do caráter nacional ou do grupo social em causa 
AS PRESSÖES E ANTAGONISMOS NO PROCESSO DE EVOLUCÃO SOCIAL

A $\underline{\mathrm{S}} \underline{\mathrm{P}} \underline{\mathrm{E}} \underline{\mathrm{C}} \underline{\mathrm{T}} \underline{\mathrm{O}} \underline{\mathrm{S}} \underline{\mathrm{C}} \underline{\mathrm{O}} \underline{\mathrm{N}} \underline{\mathrm{J}} \underline{\mathrm{U}} \underline{\mathrm{N}} \underline{\mathrm{T}} \underline{\mathrm{U}} \underline{\mathrm{R}} \underline{\mathrm{A}} \underline{\mathrm{I}} \underline{\mathrm{S}}$

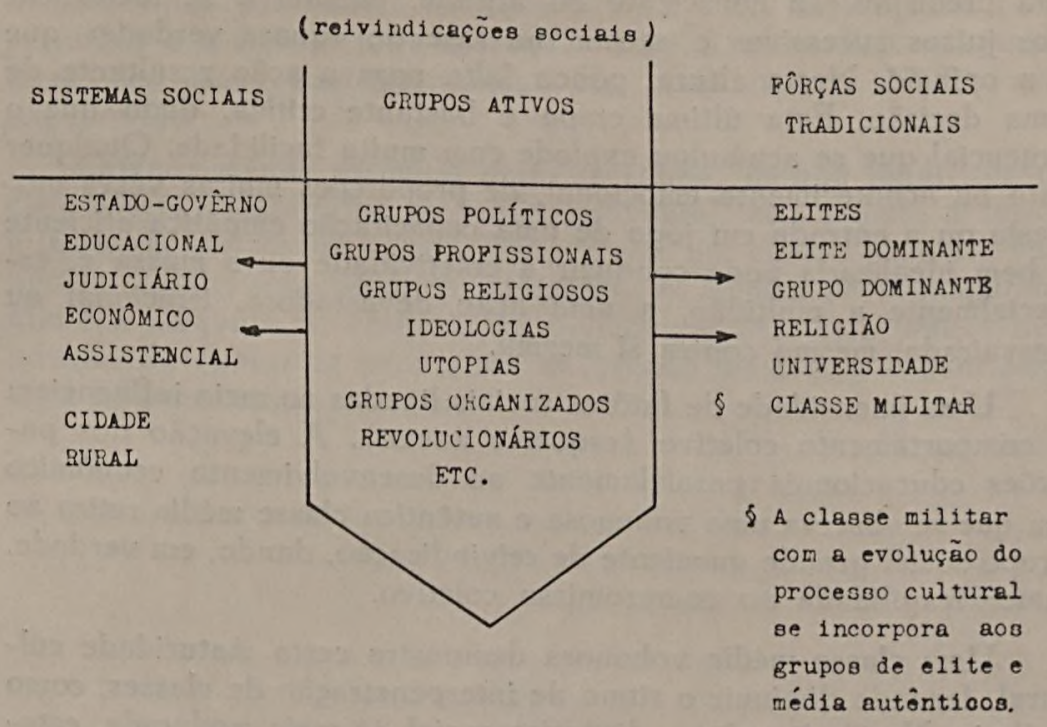

\section{ASPECTOS ESTRUTURAIS}

Hipóteses: A. Reajustamento harmonioso

$\begin{array}{ll}\text { (Toymbee) } & \text { B. Instabilidade Social e Política } \\ & \text { D. Revolução (violência ou ilegalidade) }\end{array}$

(pausa de processo evolutivo)

(retomada da posição anterior ou inicial)

Observação: O Sistema Educacional é o que se apresenta mais eficiente para uma conclusão harmoniosa, desde que obedeça a uma proporção satisfatória entre expansão e evolução. O Sistema Judiciário é o regulador de direitos e deveres da orgânica social e deve ser acessivel a todos.

ADESG - 1962 - José de Almeida Rios - «Paradoxos, Pressões e Antagonismos do processo de evolução social».

vai cedendo, aos poucos, em seus valôres tradicionais e se transformando, e a outra é contida nos seus avanços e se adapta a posições menos ambiciosas. É fácil compreender o mecanismo. Se a formação coletiva de opinião é a soma e o consenso comum de interêsses e aspirações pela sucessão de «juizos de valor» conferidos seguidamente, a verdade, sujeita apenas a uma inclinação, vai firmando mais a sua autenticidade. Se ocorrem os movimentos 
sociais a busca de reivindicações, mecanismo mesmo do processo de evolução social, cada vez mais os grupos se homogeneizam em sua predisposição consciente ou atitude, passam a se identificar por juizos sucessivos e entram na fase de «quase verdade» que é a opinião. Nesta altura, pouco falta para a ação resultante de uma decisão. Esta última etapa é bastante crítica, dado que o potencial que se acumulou explode com muita facilidade. Qualquer fato ou acontecimento emocional, de proporções muitas vêzes modesta ou a entrada em jôgo de uma capacitação empática eficiente e bem idealizada pode conduzir a coletividade ou a massa e, especialmente a multidão, a uma ação devastadora, irracional ou desvairada, mesmo contra si mesma.

Uma imensidade de fatôres sociais ligados ao meio influenciam o comportamento coletivo (esquema anexo). A elevação dos padrões educacionais paralelamente ao desenvolvimento econômico em que se observa uma volumosa e autêntica classe média retira ao grupo social grande quociente de reivindicação, dando, em verdade, maior fragilidade ao compromisso coletivo.

Uma classe média volumosa demonstra certa maturidade cul tural, fazendo diminuir o ritmo de interpenetração de classes, como é óbvio. Nesta situação, a dinâmica social, já mais moderada, estabelece uma maior racionalidade na forma dinâmica de opinião pública. Pelo contrário, a existência de uma classe popular de proporções maiores, com grande número de reivindicações a fazer (esquema anexo), pressiona as fôrças sociais tradicionais, provocando maior elo de solidariedade e tornando o grupo social considerado bastante sensivel a movimentos coletivos. Nesta altura, como é natural, surgem correntes derivativas irracionais, inconscientes e, muitas vêzes, contraditórias. Tais variações enfraquecem a sintonia de homogeneidade, diminuindo a própria fôrça de unidade partida do coletivo. O nacionalismo exacerbado é um dêles. Aqui uma soma enorme de interêsses normais e anormais se associam, inclusive a descendência estrangeira. A atividade politicopartidária personalista ou individualista, esperançosa da conquista de situações materiais e sociais, sem dispor de qualificações con-
venientes, seria outro exemplo.

Em uma sociedade, os acontecimentos que se desentolam em seu meio e sua interação não podem ser compreendidos senão pela pesquisa, pelo estudo, pela análise e pela avaliação e critica de
seus complexos dominantes.

A atitude provocada e a sensação de um «juizo de valor» que bruscamente, dada a natureza númena da mente humana e a ca-
pacidade empática de cada qual. É nesta altura, que nos extasia a 
segurança e a firmeza cientificas, que prenunciam sossêgo, serem desautoradas pela arte com sua vocação para agitar. Não é outro - motivo por que assina Georges Braques: «A arte é feita para perturbar e a ciência para sossegar» (cit. GAETON PICON, "panorama des idées contemporaines» Ed. Gallimard, 1957, Paris pág. 441).

Quanto menos evoluída uma sociedade, mesmo tendo alcançado niveis satisfatórios de renda individual, está sujeita a falsos e instáveis «juizos de valor», tornando-se um campo bastante vulnerável contra seus próprios interêsses. A técnica de propaganda, que é a máquina de contrôle da opinião pública, está hoje à disposição de quaisquer propósitos de grupos mais bem organizados e de Estados estrangeiros... 


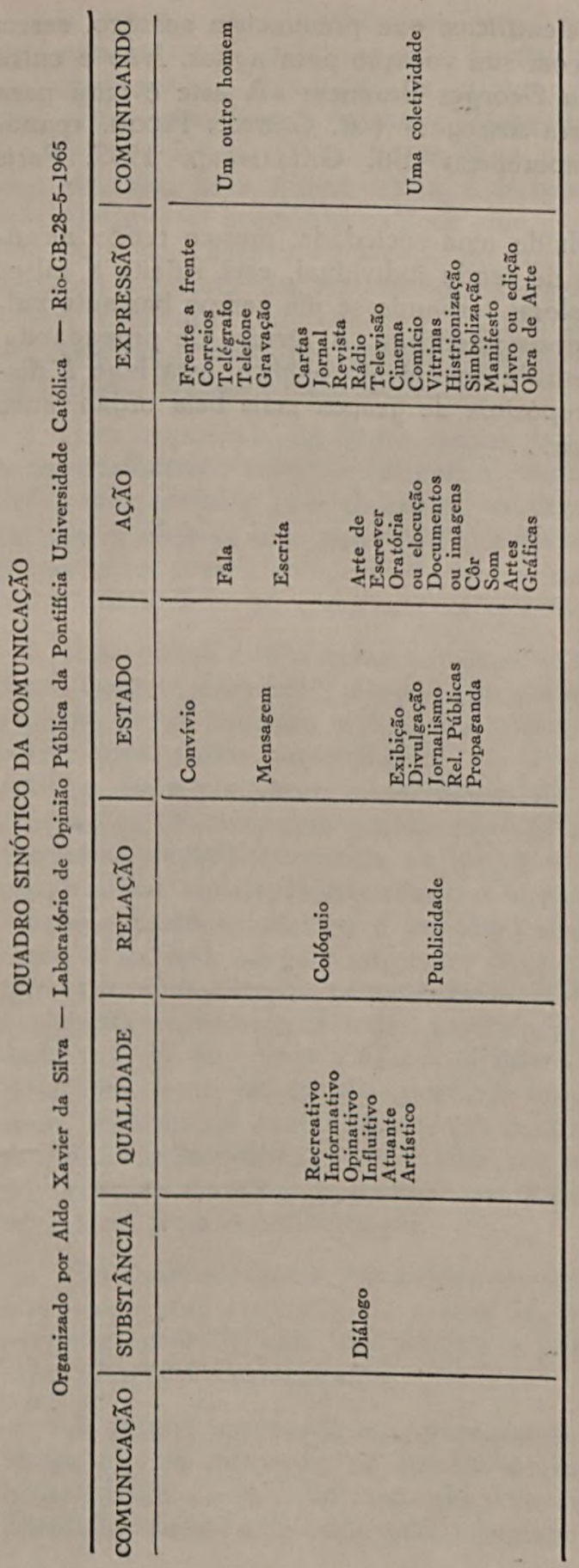


Como o Estado apóia a sua autoridade em várias expressões de fôrça, tem êle que lançar mão do que possui de mais eficiente e adequado para dominar os impulsos emocionais coletivos, lançando mão de recursos que possam sustentar as instituições, mas, ao mesmo tempo, não desestimular ou desanimar as atividades e iniciativas individuais, na determinação de inovar, renovar, transformar e reformular a estrutura social, fundamentando a Evolução. Impõe-se hoje uma ditadura técnica em qualquer expressão de poder, visando lançar a Tecnologia na formulação dos negócios do Estado em benefício da Nação, sem perder de vista, contudo, a resultante entre determinações técnicas e imposições políticas. Tendo sempre na mentalidade da economia politica a opinião tradicional alicerçada nas revisões dos Objetivos Nacionais Permanentes, precisa o Estado Moderno encontrar uma mística, uma doutrina e um conceito mais profundos que possam inspirar a confiança da Nação acima das correntes de opinião pública.

Muitos Estados contam, pois, com fontes formais de poder politico que se sobrepõem às fontes reais de poder politico, muito sujeitas à instabilidade e insegurança, mesmo nas mais velhas e sedimentadas culturas sociais. A Coroa Inglêsa é uma fonte formal de poder politico que impôs a resignação do rei Eduardo VIII, contra a opinião nacional e estrangeira. Falou mais alto o interêsse do Estado ao persistir na bandeira de uma moralidade que mantém mais sólidos os laços da Commonwealth, fundamento da economia inglêsa. A ditadura técnica financeira dos E. U. A. impediu o aumento do preço do aço que era uma imposição de grandes emprêsas norte-americanas. A filosofia de vida democrática daqueles governos náo conseguiu, durante muitos anos, a permissão de voto aos negros e um grande condado inglês só veio a ter direito de voto em 1914. Exatamente no chamado padrão democrático grego menos de $15 \%$ de cidadãos tinham o direito de votar. A nova constituição da República Federal Alemã consigna a perda de emprêgo e da propriedade para os condenados de subversão. O Presidente De Gaulle tem o direito de dissolver a Assembléia. Esta é quase sempre um desfecho resultante de uma homogeneidade de sentimento e interêsse das diversas classes sociais, especialmente a faixa do grupo médio, aginde contra um grupo ou elite oligárquica que age, ferindo-a profundamente em seus anseios.

A necessidade e a sintonia de interêsses podem estabelecer uma aglomeração de grupos sociais diversos. A experiência de Sherif e Carolyn («Groupe in Harmony and Tension»- N. I. Harpers, 1953) demonstrou que dois grupos rivais especialmente colocados um diante do outro e «fabricada» uma dificuldade a que somente a reunião dos dois poderia resolver a união se estabeleceu, mesmo que a reação de líderes de ambos os blocos se fizessem sentir 
temendo perder as posições de liderança. Dentro da fase experimental por que passa e psicologia social, é possivel, contudo, estabelecer algumas idéias reguladoras da formação da sociedade dentro de uma dinâmica integrada de evolução social e a psicologia da coletividade. Os processos psico-sociais encontram-se freqüentemente dependentes dos vastos processos sócio-culturais e são «capturados». É valioso considerar, pois, que as ocorrências psicosociais causadas e absorvidas pelos eventos sociais podem ter sido, na sua acumulação sucessiva de aglomeração de grupo nos seus movimentos de reajustamento, readaptação e sintonia de sentimento, provocados pela homogeneidade de aspirações, interêsses e posições de maior vulto. A mudança de atitude pode ser um produto secundário de grandes e acumulativos processos sociais. Como bem diz William Lambert: é «como um ruído feito pela máquina social em movimento». A sequiência, pois, de um processo dinâmico de formação da opinião pública, ou melhor, a base es trutural de sua manifestação conjuntural parte realmente da «acumulação» de processos psico-sociais provocados e influenciados pelo processo social de evolução, baseado nas mesmas características de formação do caráter e que, em uma soma total de formação, corresponde a uma visão global ou macroanálise, sendo possivel proceder-se a uma microanálise de parcelas.

Os processos psico-sociais são importantes e medeiam ou integram os eventos e os fundamentos do processo social de ev́olução. $\mathrm{Na}$ posição eclética com mais fácil raciocinio e menor complexidade intenta-se aprender a noção de que os processos psico-sociais são sempre secundários aos processos sociais e por êstes causados, capturados ou absorvidos.

MacClelland, da Universidade de Harvard ( The Achieving Society», Princeton, D. Van Nostrand Co., 1961) enfatizou de modo especial a importância de fatôres psico-sociais no desenvol vimento econômico. Estudou e pesquisou acêrca da influência da educação infantil na sua fórmula tendente a propiciar independência precoce tal como sempre aconteceu na seita protestante. Procurou demonstrar a relação da mudança de caráter e de atitudes na grandeza e decadência dos grandes impérios. Sugere o autor que, se uma sociedade desejar aumentar sua riqueza econômica, deverá olhar para seus recursos humanos (entre outras coisas), em têrmos de motivação profunda e precoce, reordenando a vida familiar, de acôrdo com as crescentes oportunidades econômicas (sistematização de W. LAMBERT, pág. 2).

$\mathrm{Na}$ atual fase de evolução social é dentro da aceitação para formação do Estado Moderno que englobou quase tôdas as as pirações e interêsses de reivindicações populares das ideologias em moda, especialmente o socialismo, vemos a necessidade de formar a juventude nos preceitos fundamentais que conduzam a 
maior atenção para o gênero humano nas suas necessidades primárias e determinantes para acomodação e concordância de participação das restrições da vida social visando estender ao maior número, senão a todos, os benefícios da evolução cultural.

Acêrca da teoria de MACClelland, identificando nos jogos possibilidades de encaminhar fatôres favoráveis de personalidade, apesar de difícil comprovação, Roberts e Sutton-Smith tentaram uma sistematização na figura seguinte:

\begin{tabular}{|c|c|}
\hline Nível Sócio-cultural & $\begin{array}{l}\text { 1. Problemas de ma- } \\
\text { nutenção cultural }\end{array}$ \\
\hline Nivel Psico-social & $\begin{array}{l}\text { 2. Práticas de socia- } \\
\text { lização (em qual- } \\
\text { quer idade) }\end{array}$ \\
\hline
\end{tabular}

4. Criação e seleção $\longrightarrow 5$. Enculturação e de jogos de estratégia, azar e habi- "amortecida" lidade física processos culturais

Conflito sôbre respon- 56 . Adição a modesabilidade e resul- los (conflitos tantes de atitudes não resolvidos) ou estilos competitivos.

Caminham ou devem caminhar juntos os modelos educacionais e a formação de uma sadia opinião pública. É preciso que se afirme, nos têrmos devidos, a importância que devem ter as necessidades na dedução de uma meia-verdade construtora da atitude. Tanto no equilibrio como na formação da opinião, muitos subsídios podem ser transferidos da psicologia social para os modelos educacionais. Finalmente vamos transcrever, como curiosidade,

\title{
OPINIÃO PÚBLICA
}

(Um tipo de formação de atitude c opiniăo)

\author{
CAMPO ECONÔMICO
}

\begin{abstract}
Hábitos e mentalidade inflacionários e caracteres tradicionais negativos para o desenvolvimento econômico. Pouca propensão para a poupança, descaso para os custos e inclinação para gasto $s$ acima das possibilidades de receita. Pouca atenção para o des perdício. Despreocupação para os custos de produção, devida à vigência de um semi-sistema monopolista oficial ou oficioso, a cobertando os riscos da atividade privada, Persistência de uma valorização artificial da produção industrial ao invés de proteção va pioneirismo industrial nacional (monopólio disfarçado). A cumu lação de estoques de matérias-primas e produtos manufatu rados, mascarando uma realidade.
\end{abstract}

A. Ataque à inflação, restrição do crédito e ao aumento de salários. Reajustamento realístico dos preços dos produtos agropecuá-

B. Resistência da opiniño pública em nome do hábito e da mentalidade inflacionária (grupo social - consumidores e usuários) e pelo sistema de desinterêsse pelos custos e o trabalho especulativo como método (grupo social - empresários)

SISTEMA SÓ́CIO-ECONÔMICO _ 1. Readaptação dos dois grupos

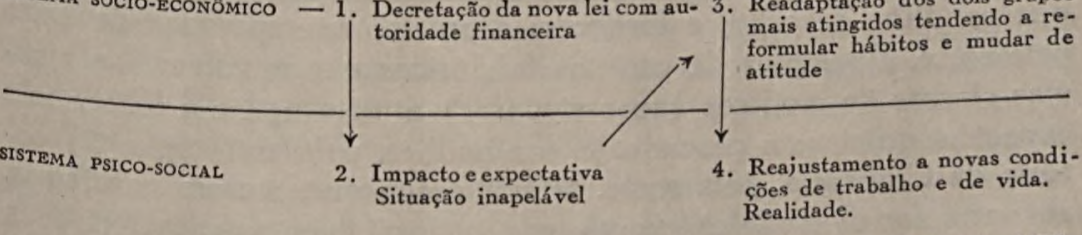


PORMAÇÃO DA OPINIÃO PÓBLICA

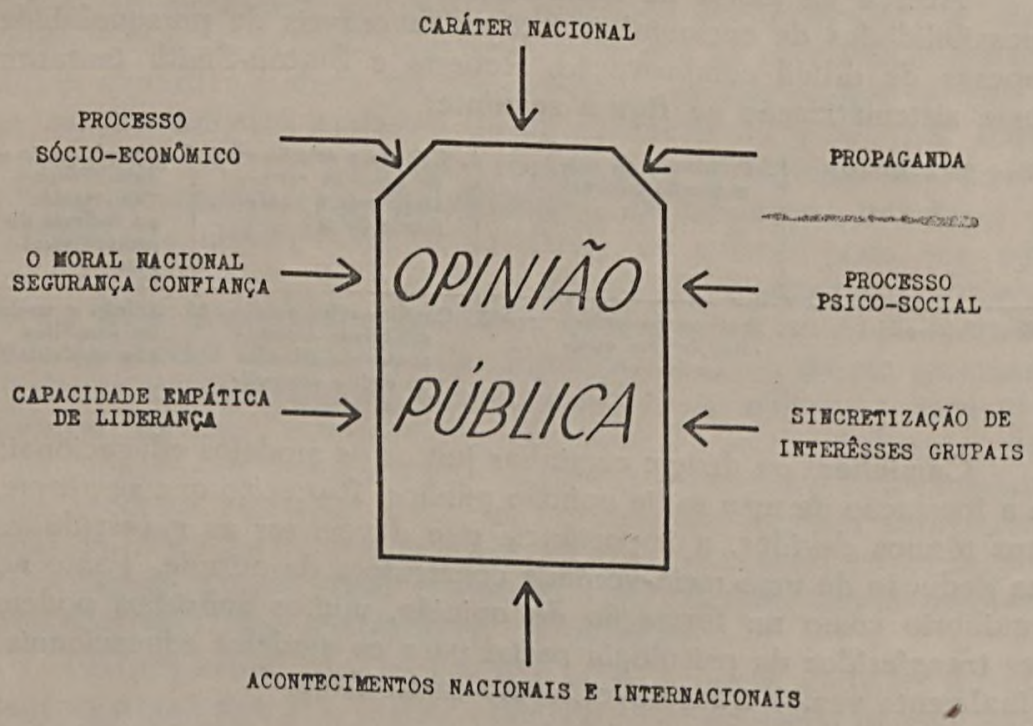

perfunctòriamente uma experiência e algumas conclusões especulativas levadas a efeito por John Roberts e Sutton-Smith ( Ethnology, vs. 1, 2, 1962) sôbre vários tipos de jogos e atitudes.

Pensa êle que existem três espécies de jogos mais importantes modelando diferentes estilos ou atitudes de competição. São as seguintes: 1) jogos de capacidade fisica, tais como corridas a pé, modelam atividades culturais como capturar uma ovelha tresmalhada do rebanho e permitirem o ensaio de atitudes e esperança no sucesso, pelo exercício da velocidade e energia; 2) jogos de estratégia, tais como o pôquer e o bridge, modelam as atividades do mercado e facultam o ensaio de atitudes de esperanças no êxito pelo exercício do poder de decidir com astúcia e inteligência; 3) jogos de azar, como a roleta, refletem atividades como descobrir um filão de ouro, e fornecem a prática na esperança de êxito pela sorte. Exemplos de estórias folclóricas que envolvem as mesmas classes de modelos expressivos: 1) a tartaruga e a lebre, pela capacidade física; o pescador e sua mulher, pela estratégia; 2) estória da Cinderela, pela sorte. Vimos assim que, mesmo nos jogos, encontramos os modelos expressivos que espelham as características da evolução social: a estratégia, a energia e a aventura. 


\section{PROPAGANDA}

É uma técnica e método para contrôle de opinião pública. Para execução de um programa de propaganda, mister se faz um estudo de situação que abrange características evolutivas com suas modificações, transformações e inovações, havendo necessidade de um ajustamento de objetivos a perseguir e finalidades a serem atingidas. Sem dúvida, a estrutura social impera soberana na natureza de finalidades com relação correta de veículos e o campo social a ser impressionado. É muito importante firmar bem a atitude ou predisposição, pois que as fases sucessivas de «juizos de valor» acumulativos precipitam a decisão. Certas características de propaganda, segundo os fins, são de execução difícil. A mudança de hábitos, de condições e situações impregnados no caráter do povo ou do grupo social, torna-se uma tarefa de longo alcance. A opinião coletiva, em sua fase de ampliação e de agregação grupal de sentimentos vários, passiveis de um recondicionamento, é bastante sensivel a uma verdade universal ou de maioria. Por outro lado, a coletividade ainda se impressiona muito com a ação do poder sem contestação e tão forte que pouca possibilidade haja de destitui-lo. A fôrça ainda é maior quando se vislumbra uma verdade de conduta satisfatória capaz de elevar o padrão de conceito generalizado. O curioso é que o senso coletivo ainda se inclina muito para um govêrno forte, o que demonstra a fôrça de uma tradição provinda da inicial organização das tribos.

A grande tarefa da propaganda é transformar a atitude e predisposição a que se adicionam as possibilidades constatadas da pesquisa, estudo e análise do meio, figurando ainda uma meiaverdade, e controlar o resto do caminho a seguir até a decisão, passando pela opinião. Precisa atingir finalidades que são uma etapa intermediária entre a decisão e a ação. $\mathrm{O}$ objetivo revela a fase final onde se firma certa estabilidade e constância de ação que poderão transformar-se em novos valôres ou outras fisionomias de caráter ou hábito social (esquema anexo).

São tão variadas e multiformes as maneiras de comunicações na técnica e no método de propaganda moderna que uma satisfatória exposição necessitaria de um verdadeiro curso regular. Para quem está bem familiarizado com os assuntos de psicologia social e está bem informado acêrca do meio e das camadas sociais que precisa impressionar, não apresenta maior dificuldade a elaboração de um plano de propaganda. A adaptação de finalidades e objetivos aos recursos de comunicação, com suas particularidades e peculiaridades, a natureza do problema, assunto ou artigo a sugerir para a decisão e a seleção de tipo de público que deva ser trabalhado, decorre da experiência, da pesquisa, da análise e da crítica. 
$\mathrm{Na}$ forma ilustrada audiovisual, dificilmente consegue-se a primeira manifestação de atenção para a comunicação quando está em foco um acontecimento que esteja empolgando, no momento, o público visado. Nesta ocasião é válido apenas um «slogan» rapidissimo que lembre uma seqüência de comunicações anteriores. É péssimo momento de encetar uma primeira etapa de comunicação. Os anúncios seguidos e longos em tais momentos são contraproducentes.

Outra modalidade desaconselhável é a utilização de superlativos qualificativos.

Um ponto importante é conseguir constatar e interpretar bem uma incoerência e apresentar a solução certa.

Certas conexões adequadas e válidas despertam atenção e podem apressar a decisão. Conta Siegfried que em uma viagem a Nova Iorque teve oportunidade de acompanhar a ação de dois engraxates. Em um dos lados da 5 Avenida um profissional volante atendia constantemente a fregueses em fila e do outro, um seu colega, em meia hora, não conseguiu atender a um só freguês. Verificou que o primeiro, quando apregoava seus serviços, lembrava que no dia seguinte era domingo e não havia engraxates.

Muito delicada e difícil é a comunicação ilustrada por meios jocosos e pitorescos. O sentido de ridiculo é desalentador para a técnica de propaganda. Em princípio, o contato deve ser firme, decidido, sério, convincente e sem hesitação.

$O$ estudo e a pesquisa, tendendo a investigar a atitude e as reações que possam definir a opinião pública, constituem; de fato, uma ciência nova. A arte na pesquisa da alma humana exige um atributo especial e discernimento cultural variável permitindo excluir das conclusões os fatos e as emoções que alteram profundamente o sentido exclusivo da pesquisa. Por outro lado, a capacitação da comunicação determina uma condição pessoal própria. A pesquisa segmentária de opinião, como base fundamental para o plano de propaganda, é acompanhada de erros de interpretação
fundamentais.

Eis porque H. H. REMmers ( «Introduction to Opinion and Attitude Messurement», Harper \& Brothers), diz: «é sempre possível e desejável fazer levantamentos, isto é, examinar segmentos de opinião pública. Mas, sempre que se puder realizar um censo completo, há boas razões para preferi-lo».

Jean-Marie Domenach ressalta o papel da propaganda subordinando a opinião pública. Evidentemente tal influência decorre 
substancialmente das condições do meio social. Mesmo na sociedade armada dos mais evoluídos níveis culturais, o pensamento coletivo baixa bastante o seu padrão de discernimento. Para William Albi ( Public Opinion») a opinião resulta de um cotejo de juizos, de uma escolha e de um julgamento. O estímulo das controvérsias, especialmente no campo político, é tanto mais dinâmico quanto mais pobre de tradições e com condições econômicas precárias. Aqui a propaganda surte efeitos especiais na área política, onde medram a demagogia e a aventura. Nestas condiçóes, agigantam-se os valôres da propaganda e o povo situa-se em posição indefensável, comprometendo a capacidade e a responsabilidade do Estado Moderno. Mesmo as nações mais amadurecidas compreenderam esta verdade e se armaram com específicas Expressões de Poder onde é fornecido um valor relativo à opinião coletiva como fonte decisiva de autoridade política. Realmente o govêrno, onde se constitui a formação do poder pela vontade popular, é apenas o instrumento do Estado. O primeiro tem uma temporariedade de mandato frente à perenidade do Estado.

O contrôle e a manipulação das atitudes denominam-se propaganda. Esta é indiferente à verdade enquanto comumente se a diferencia da educação porque esta deve ser fiel a ela. Os principios da propaganda incluem ora as causas, ora os efeitos predisponentes, prováveis, estáveis, mobilizáveis, redutiveis ou irredutiveis, assim :

1. ${ }^{\circ}$ ) A intenção do propagandista onde existe um propósito interessado; naquela não-intencional não é levado em consideração - efeito social das próprias ações;

$2^{\circ} .^{-}$A percepção onde a ação procura fazer sobressair sua situação de estímulo de seu campo de competição; uma série de fatôres estranhos servem de complementação eficiente ao problema focalizado em tese;

3. ${ }^{\circ}$ O tipo de propaganda: revelada, revelação retardada ou oculta. No primeiro, usa-se a sugestão direta e o fim da propaganda fica claro desde o início; na segunda, a revelação retardada exige um certo período cheio de motivações preparatórias conexas e auxiliares, como se houvesse uma ação preparatória de terreno; no tipo oculto, a propaganda evita revelar o seu objetivo;

$4^{\circ}{ }^{\circ}$ ) $O$ principio das atitudes conexas; existe a suscitação de atitudes conexas que servem de instrumentos para atingir a integração desejada. Estímulos variados permitindo atingir predisposições e atitudes de um maior número impregnam a motivação e o objeto principais da propaganda. Um hotel que comunica situação ideal de proximidade comercial, rêde de rádios e televisão nos quartos, desperta outras atitudes interessadas que não sejam simplesmente aquelas de um hotel - hospedagem; 
5. ${ }^{\circ}$ A integração desejada identifica uma ação convincente que possa predispor a um fim comum. Evidentemente o fato revela uma esperança que poderá chegar ou não a uma integração. Diversos fatôres a serem explorados, como a emoção, por exemplo, podem atingir os fins visados. (BIDDLE, «A Psychological Definition of Propaganda» J. Abn. Soc. Psychol, 1931). Acredita o citado autor que, teòricamente, qualquer emoção pode ser transformada em qualquer ação por meio de manipulação adequada e hábil. Assim a foto de uma linda môça tomando um suco de tomate não só atrai a atenção como acarreta uma atitude favorável. Acreditamos, contudo, que certa conexão é indispensável na apresentação da complementação;

6. ${ }^{\circ}$ ) A esfera da imprevisibilidade onde, salvo no caso de propaganda oculta, a partir da compreensão até a ação, existe uma esfera imprevisível, devido ao caráter temporário da propaganda, a presença de propagandistas competidores, membros interessados diretos da ação etc. Mutitos recursos ocorrem para vencer esta fase negativa do processo de propaganda ao lançar-se mão de complementos de prestígio, a primazia nas originalidades
dando a afirmação das primeiras impressões.

$\left.7^{\circ}\right)$ A contrapropaganda se impõe quando atitudes de conflito impedem a integração desejada. A contrapropaganda relativa dos fabricantes de cigarros, que são obrigados nos E. U. A. a anexar um aviso do prejuizo grave à saúde, pode ser aquela de indicar a região balcânica onde existe o maior número de centenários e êles não tiram o cachimbo da bôca. Pode, outrossim, contrabalançar com o equilibrio psíquico que o fumar pode despertar, aliviando o ataque das doenças degenerativas da atual civilização.

$\left.8^{\circ}\right)$ Enfim, o princípio da persuação, onde o método é utilizado como forma complementar. Uma artista popular é «persuadida» por algum ganho material direto a deixar-se fotografar usando certos produtos de toucador, persuadindo a que outras
desejem segui-la.

Na contrapropaganda, existem três normas mais importantes a serem seguidas:

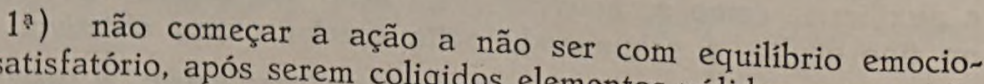
nal satisfatório, após serem coligidos elementos válidos, preparação

$\left.2^{a}\right)$ procurar ridicularizar e desmoralizar com argumentos fortes, se possivel de incoerência, e aproveitar, ao máximo, os recursos da crítica e da lógica para estabelecer um jôgo irônico, caricato e mento jocoso tem aqui muito em tonalidade bem elevada. $O$ ele na propaganda; 
$3^{\text {a) }}$ insistir e firmar contradições nos erros informativos e nos disparates.

A contrapropaganda exige tão-sòmente os conhecimentos indispensáveis da motivação da propaganda em tela como um adicional substancial de novas caracterizações, aspectos e ângulos.

Um dos pontos em que mais desperta atenção o problema da opinião pública é aquêle da censura. Esta sempre existe dentro de uma formalidade social, contudo é possível estabelecer três características especiais: a censura social, a legal e a ética.

A censuta social é a decorrência de uma atitude e de opinião pública no ponto em que as comunicações possam ferir o padrão de convicção moral da sociedade em causa. Existem alguns agrupamentos sociais que se entregam especificamente a esta fiscalização e cobram da autoridade pública a ação repressiva correspondente ou atuam com uma contra-informação prejudicial aos objetivos e finalidades da ação desencadeante. Em alguns países tais iniciativas assumem um caráter bastante importante, atingindo todos os veículos de comunicação, especialmente o cinema, a televisão e o rádio.

A censura legal tanto repousa em uma atitude de prevenção, jogando com a responsabilidade de cada qual em vista dos textos legais, como, em períodos anormais, faz diretamente uma fiscalização prévia do objeto das comunicações ao público. No primeiro caso, ocorre a punição «a posteriori» da ação transgressora. Contudo, muitas vêzes, a ação e o impacto do veículo de comunicação são por demais bruscos e violentos, pela amplitude e pela agressividade imediata, tal como se nota no rádio e na televisão. Não é outro o motivo por que o Estado, ou toma a sua responsabilidade tais empreendimentos, ou os coloca sob forma de concessões precárias.

A censura ética é devida ao nível educacional profissional dos empresários e concessionários das emprêsas privadas de comunicações, especialmente jornais, revistas, publicações, estações de rádio e televisão. $\mathrm{O}$ problema comercial neste caso pode, em virtude de nivel cultural deficiente da sociedade e do público, em causa, baixar bastante o grau de ética.

Em se falando de censura, ressalta logo o assunto de liberdade.

É determinante para o processo de Evolução a liberdade de idéias e de pensamentos. Com a possante técnica de propaganda de nossa época, aquela liberdade, com licenciosidade e irresponsabilidade, cerceia, pelo temor, a própria liberdade em benefício de interêsses particulares ou de grupos, ferindo, profundamente, o grande fundamento democrático de igualar dentro da desigualdade. 
Por outro lado, sendo a propaganda, muitas vêzes, uma violação de consciências, pode praticar, sob as vistas do Estado Moderno, um crime de despersonalização. Parece ser pior do que a morte física.

Foi por tais motivos que o Estado Moderno, já amadurecido pela Evolução satisfatória, defende os interêsses da Nação, impondo, em muitos casos, uma ditadura financeiro econômica contra a ação de govêrno provocada pela opinião pública, e, mesmo àquela do povo, em nome do Estado. Alguns Estados lançam mãos de outras expressões mais fortes de poder para o mesmo fim quando não dispõem, inclusive, concomitantemente, de uma Fonte Formal de Poder Político de natureza tradicional - Coroa. Alguns se acobertam na expressão jurídica, outros na forte estrutura social e alguns ainda, em fase menos evoluída, na sua classe militar. Existem apoios também na tradição religiosa.

Um Estado que conseguiu fundamentar na filosofia de vida democrática as suas leis objetivas e afirma vitoriosamente suas leis subjetivas tem, convencionalmente, cerceada a liberdade com muito maior intensidade do que nas democracias incipientes e nos sistemas ditatoriais. Aquelas leis decorrem da sanção do povo onde o «número de patrões» é muito maior para ser contentado do que nas ditaduras e democracias incipientes. Nestes últimos casos, as questões são bem mais limitadas e os donos a contentar, geral-

mais ou menos estamentada.

Ao sugerirmos a filosofia e a doutrina de Segurança Nacional, pretendemos bradar em um campo onde possam existir Estadistas. aquêle perene e êste transitório, já dé entre Estado e govêrno, gócios de Estado e avidez por assuntemonstra desinterêsse por neo instrumento daquele... mas atua in govêrno. E êste é apenas transitoriedade. Sem campo de ação, o Estadinadamente na sua decorrer daí, igualmente, a confusão Estadista retraitu-se. Pode dade; equivoco entre democracia e liberdre liberdade e licenciosifilosofia com forma ou sistema de liberdade e incompreensão da vêrno, êste como seu instrumento govêrno. O Estado e não o gogovernar com o povo e para o povo, resgaresponsabilidade de evolução social e da ciência e povo, resguardando-se dentro da contra a Nação.

Nenhuma atitude determinante, absolutista e dogmática da liberdade pode eliminar a pluralidade das considerações nem a relatividade das perspectivas. A relação e o determinismo, o prag matismo e a história monumental não podem também desaparecer senão na medida em que se comprometam com as atividades vitais a cujos interêsses devem atender. Eis porque a liberdade, possivel 
na teoria e efetiva na prática, nunca é inteira. O passado do indivíduo limita o seu jôgo na iniciativa pessoal e a situação histórica fixa a possibilidade de ação política. Uma filosofia democrática de relaçães se define quando existe o cidadão que reconhece seus deveres frente ao Estado e êste reconhece os direitos daquele.

Tanto maior o senso de responsabilidade quanto menor o sentido de liberdade individual. Quanto maior o nivel cultural de uma sociedade mais ela leva a consciência de responsabilidade. Quanto mais evoluída a civilização atingida por um grupo social, maior restrição da liberdade individual frente aos interêsses coletivos. A única forma de govêrno passivel de evolução é a que se aprofunda nos ideais da filosofia democrática de relações, isto é, «a igualdade dentro da desigualdade» e a «mesma oportunidade a todos». Poderá o Estado Moderno confiar em um seu instrumento - o govêrno onde a fonte real de poder político é gerada sob os influxos os mais variados, instáveis e flexiveis, gerada em condiçóes de instabilidade psíquica (natural e artificial criada pela técnica de propaganda de grupos interessados, nacionais e estrangeiros), movida sua decisão coletiva de acôrdo com fatos e acontecimentos imprevisiveis e nem sempre verdadeiros, na irracionalidade, já pela insipiência educacional, já pela forma coletiva de pensamento? Não é outro o motivo por que os Estados mais desenvolvidos e evoluídos lançam mão das Expressões de Poder, citadas anteriormente, para impor atitudes mais reais e racionais para conciliar eficientemente assuntos politicos e técnicos de sua responsabilidade e os problemas politicos, onde estejam válidas a opinião pública e a atitude. Hoje, o Estado Moderno se vê a braços com os programas, planos e Planejamentos a longo prazo e baseados na análise, na crítica e no estudo estrutural inteiramente fora do alcance público que se emociona com os acontecimentos conjunturais, simplesmente. Sòmente assim, será possível aproveitar ao máximo os recursos e meios disponiveis para cumprir fielmente «aquêles fundamentos essenciais da filosofia democrática de relações», de sua inteira responsabilidade.

Terminando estas considerações, ainda pensamos ressaltar o grande fator de formação da opinião pública, especialmente, no campo político. Para Biddle, já citado, a emoção constitui um ingrediente manipulável ao sabor de quaisquer interêsses. É difícil encontrar outro impulso que possa distorcer a opinião pública e a atitude coletiva do que a emoção. A facilidade com que se constrói uma «imagem estereotipada» e o tremendo impacto que pode causar na decisão coletiva sujeita os destinos de uma Nação a um caminho desastroso, conforme os recursos e meios empenhados e interessados. Ela pode causar danos irreparáveis em que pêse à sanção legal. A consciência coletiva manipulada pela téc- 
nica de propaganda moderna pode tornar $\sim$ se objeto de uma verdadeira violação ingênua dos direitos e da Segurança da nacionalidade.

ESQUEAYA DA DINÂV.ICA DA PFOPAGANDA

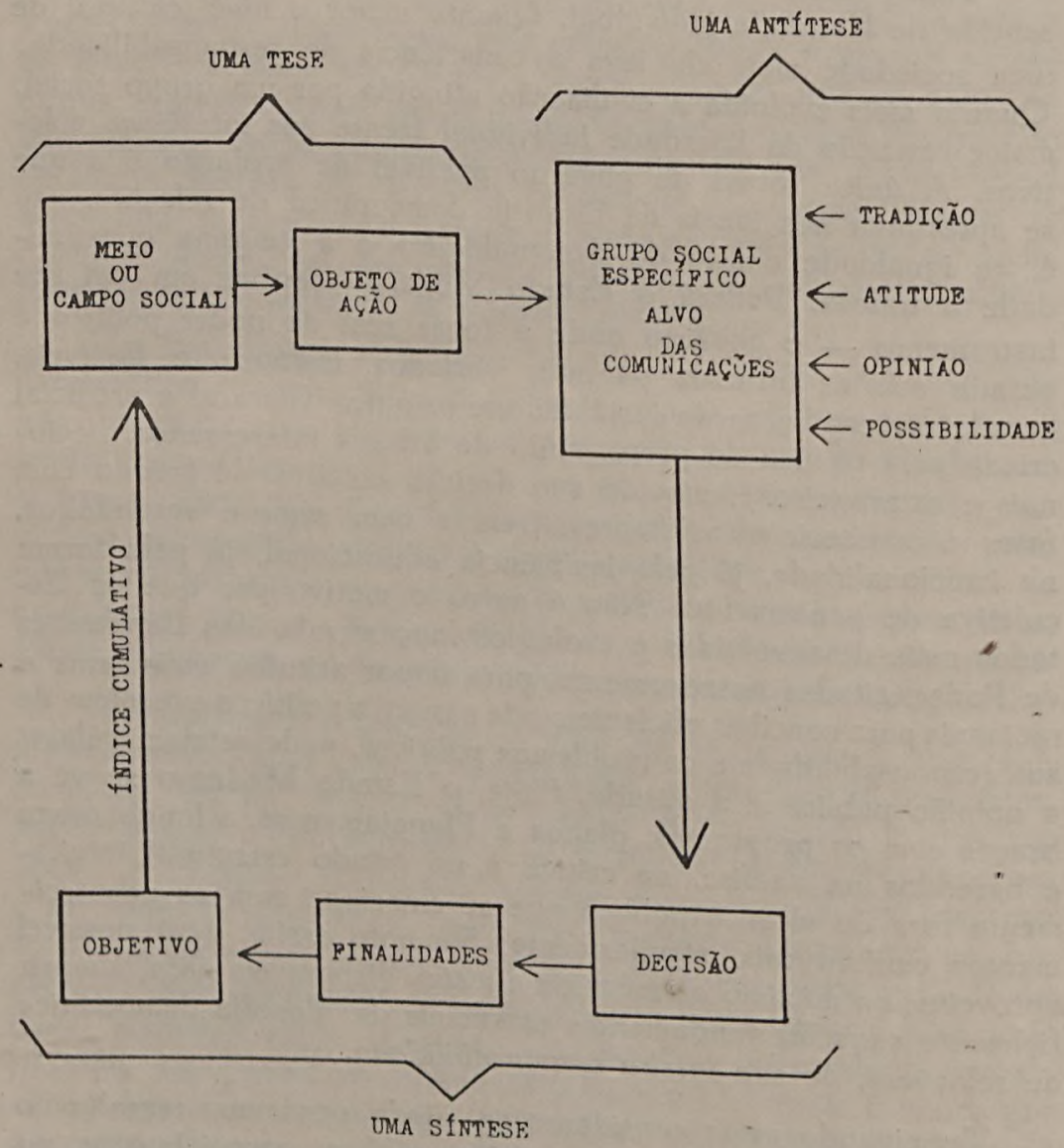

DECISÃO

A seqüência da mobilidade do pensamento coletivo, partindo da atitude que é uma predisposição, passando pela opinião que já é uma inclinação para a verdade, chega à fase de decisão ou ação. Mesmo nesta última existe a exigência de um influxo capaz de vencer resistências ocasionais por preconceito, temor, responsociais que levam, muitas vérie enorme de constatações conexiais opinião já formada. 
Muitas técnicas diferentes têm sido imaginadas para o estudo, se possivel, da medida das atitudes e opiniões. Os inquéritos trabalhosos de opinião pública, onde as questóes procuram aferir indiretamente a disposição de uma coletividade pelos testes heterogêneos, se fôr o caso, de qualificação dos inquiridos, é preciso que não se sujeite o testado a uma prova flagrante de responsabilidade pessoal. Por outro lado, o objeto mesmo da inquirição deve ficar a encoberto e a dedução será feita pelas questões indiretamente sugeridas. Muitos autores têm-se entregado ao estudo da questão $\left({ }^{*}\right)$.

Quando a atitude dos elementos recrutados para pesquisas estejam já na defensiva ou em impacto por acontecimentos diretamente identificados com o objeto da pesquisa, as respostas podem sofrer deformações e a interpretação é falha. A emoção transforma, mesmo momentâneamente, uma atitude já tomada e mesmo uma opinião quase definitiva (Newcomb). Tais serviços, sob o ponto de vista político, deveriam estar a cargo de um órgão fora da influência na dinâmica do govêrno a ser destacado no campo do Estado ou da Segurança Nacional. Pessoalmente, já ensaiamos uma pesquisa no meio estudantil. A dificuldade de compreensão no âmbito do govêrno não permitiu a terminação dos trabalhos. Os resultados iniciais foram bastante significativos. $\mathrm{Na}$ atual conjuntura brasileira, o «universo» social de que faz parte o meio universitário é a classe média.

Tais pesquisas de atitude, especialmente sob o aspecto politico, são objeto de constantes trabalhos do «Social Survey», na Inglaterra e pela "Washington Opinion Research Laboratory», nos E. U. A. ligado às duas universidades do Estado e por muitas universidades especialmente subvencionadas. Outros Departamentos também fazem seus levantamentos especiais, como, anualmente, o Departamento de Agricultura, entre os lavradores.

Não poderemos expor aqui os problemas metodológicos de uma pesquisa na altura de uma fase de decisão. No entanto, poderemos sintetizar as fases devidas mencionadas por Leon Festinger, Daniel Katz e muitos outros ( $\ll$ Research Methods in the Behavioral Sciences» The Dryden Press N. Y. 1953).

1. Newcomb «Social Psychology» 1950.

2. Hartley, E. Land Hartley, R. E. «Fundamentals of Social Psychology» 1948.

3. Krech and Crutchfield «Theory and Problems of Social Psychology», 1948.

4. Gallup and Rae «The Pulse of Democracy», 1940.

5. Mosteller «Sozial Science Research Council Committee». The preelection Polis of. 1948-1949.

6. Meier, N. C. and Saunders, H. W. «The Polis and Public Opinion», 1949.

7. Cantril, H. «Gauging Public Opinion», 1944. 
1. Objetivos gerais - formulação das grandes linhas de pesquisas, delimitando o campo e os fins;

2. Objetivos especificos - os objetivos gerais são repartidos nos objetivos especificos, sendo particularizados os dados a serem colhidos e as hipóteses a serem formuladas;

3. Na amostragem duas questões são estabelecidas: a) qual o «universo» a ser explorado?; b) qual a quantidade e tipo de amostragem requeridos?

4. O questionário será de acôrdo com a modalidade de contato requerida - entrevistas, cartas, telefone etc.

5. Escolhido o método e o tipo da comunicação é feito um manual de instruções adequados para dar também conhecimento ao entrevistador dos objetivos da pesquisa e o sentido de cada questão exposta;

6. Análise do material será disposta em quadros que facilitem a seleção e a divisão das respostas de acôrdo com os objetivos
e a homogeneidade de seu conteúdo;

7. Um plano de análises é estabelecido concorde com os objetivos procurados;

8. A tabulação mecânica facilitará um volume maior de material recolhido e conforme a amplitude das questões estabe-

9. Análise e Relatório final requerem uma revisão dos trabalhos e maior exposição, com participação de maior número de técnicos e especialistas, abrangendo inclusive outras áreas do campo da atividade cultural. Um Relatório deve completar as conclusões técnica e a seqüência de informar a outros setores o método, a eficiente em outras áreas de interêsses visando levar colaboração

A pesquisa socinl

suas aspirações e interêsses, no tendências da coletividade, diagnóstico social que exige terapêtutica. na mão dos psicólogos.

Terminando, poderemos dizer que, ao ser transformada em ação e persistência de opinião, passa o grupo coletivo a incore tendências mais estáveis, o que, na propaganda, chamamos o
«indice cumulativo» (esquema anexo).

As pesquisas sociais freqüentes

ração da população e as propontes desnudam o caráter de inteaos novos valôres que identifiç̧ões de sua integração ou não Evolução. 
As necessidades sociais importantes determinam o comportamento de certos grupos. A possibilidade de ingresso no serviço público, por exemplo, sem a posse de aptidões educacionais ou profissionais convenientes que proporcionariam oportunidades na esfera da iniciativa privada, conduz certos grupos a manterem atividades politico-partidárias mais estreitas e sempre vinculadas a uma personalidade politica. No mesmo passo, encontram-se os que exploram o aspecto sentimental no campo ideológico, literário, jornalístico, religioso, etc. visando uma posição de prestígio popular conveniente. Explora-se até um têrmo inconsistente na moderna doutrina política - o esquerdismo. Quanto ao socialismo foi esvaziado na formação das democracias de nosso tempo ou do Estado do Bem-Estar (Welfare State, de Gunnar Myrdal), onde os investimentos oficiais são vultosos nas áreas da infraestrutura econômica e dos serviços públicos. Nas expressões emocionais, assume o assunto um caráter tanto mais expansivo quanto menor a substância de amadurecimento cultural da sociedade visada.

$\mathrm{Na}$ escala de ROBERT WoODWOETH as expressões emocionais são as seguintes:

a) amor, felicidade e alegria;

b) surprêsa;

c) mêdo e sofrimento;

d) ira e determinação;

e) aversão e repugnância;

f) desdém;

g) uma categorai residual.

Harold Schlosberg selecionou três dimensões:

$1^{\text {a)}) ~ g r a u s ~ d e ~ a g r a d o ~ c o n t r a ~ d e s a g r a d o ; ~}$

$2^{i}$ ) graus de aceitação contra rejeição;

3a) graus de provocação.

As motivações e as conexões empáticas em ações enérgicas, convincentes e decididas, movimentam e resultam em novos juizos, atitudes e opiniões. A perfeita exploração de situações, contingências e condições leva à reformulação de posições, concorrendo para encurtar os prazos imprevisíveis (entre opinião e decisão).

A decisão que corresponde a um resultado ou é uma incorporação de novos valôres, hábitos, padrões sociais e comportamentos coletivos de maneira durável e mais estáveis ou é uma ação. Social.

O processo continua na seqüência interminável da Evolução 


\section{DEMOCRACIA E OPINIÃO PÚBLICA}

O conceito moderno de democracia afirma a representação popular na formação da autoridade executiva, mas resguarda, com uma forte Expressão de Poder, o Estado, para que possa ditar as normas resultantes entre determinações técnicas e imposições políticas. Se bem que, na formalidade, a Fonte Real de Poder Político se origine na vontade de uma maioria da coletividade, existem Fontes Formais de Poder que ditam aquelas normas in dispensáveis, de modo que a imposição política não possa deformar a Tecnologia necessária e indispensável ao Estado Moderno para que possa, pela Economia Política, aproveitar ao máximo
os recursos e meios disponíveis.

Não poderá o Estado Moderno cumprir fielmente e com eficiência o preceito soberano da democracia de «igualar dentro da desigualdade», como uma sistemática de relações democráticas sem que seja capacitado na categoria tecnológica. A formação da Opinião Pública e o processo de evolução do caráter nacional, como ingredientes importantes da formação da Opinião do Povo, pestão sujeitos a uma série de influências variadas, espúrias e susnão é estranha a aplicaçãos nacionais e internacionais, a que armado das mais eficientes técnicas mótodo moderno de Propaganda, lação das consciências, já demonste conquista e mesmo devioem tal expressão o destino de unstram a impossibilidade de colocar do Estado Moderno.

Assim, cada país dispõe de uma Expressão de Poder com que consegue disciplinar a dinâmica do govêrno como instrumento do Estado. Na Inglaterra, existe uma ditadura técnica financeíroprojetos finan o poder de contensão da Câmara dos Lordes, nos tico que é a Coroa. O grande e a Fonte Formal de Poder Polirenúncia do Rei Eduardo VIII, acontecimento político recente da versal e do próprio povo inglês, que foi contrário à opinião uniPolitica de Segurança da «Commoi uma determinação técnica da da América do Norte, onde a dimonwealth». Os Estados Unidos de cêrca de 380 agências de finana financeiro econômica dispõe negros até há pouco não gozavam domento do Estado, onde os $50 \%$ do operariado é sindicalizado direito de voto e apenas por uma oligarquia de cúpula, muitas autoritàriamente dominado govêrno, constituem exemplo citado vêzes combinada com o

Tendo o nível de vida ascendido democracia. vinte anos, o fortíssimo vida ascendido em 15 a $20 \%$ nos últimos aço não conseguiu até hoje um discre e político da indústria do vem pleiteando. O México, que disputava aumento de preço que 
a palma do número de revoluções, encontra-se hoje na posição de vanguarda no índice de desenvolvimento econômico e conseguiu implantar uma expressão política de um Partido único do Govêrno e se arroga o luxo de querer ditar normas democráticas para suas companheiras latino-americans, tendo para isso autoridade para fazê-lo. Não sabemos o que levou aquêle Estado a marginalizar discretamente o grupo religioso. Parece até não haver representação diplomática do Estado Temporal do Vaticano, sendo como é uma nação católica por tradição. A França encontrou a sua expressão de Poder do Estado na sua estrutura social de classe média que encarnou na personalidade de De Gaulle as suas aspirações. Sacrificou a centenária cultura francesa da Argélia, contra, inclusive, a opinião de $500 \mathrm{mil} \mathrm{soldados} \mathrm{e} \mathrm{oficiais} \mathrm{que}$ lá combatiam para não comprometer a Política Internacional do Estado Francês acêrca do colonialismo político ostensivo. A Itália assegura a sua expressão de Poder na Religião Católica Romana. A Alemanha assentou -0 na sua expressão jurídica onde a subver são é punida com o banimento nacional e social (perda de emprêgo e propriedade).

Que expressões de Poder podem contar os Estados da América Latina na sua luta pelo desenvolvimento econômico?

Possuímos na América Latina uma estrutura política, social ou financeiro-econômica organizada? Existe uma ordem jurídica tradicional e estabelecida? Evidentemente não. Parece que o grupo mais disciplinado, organizado, coeso e com objetivo nacional, dado que joga inclusive a própria existência, é a classe militar. Acreditamos que seja um segmento de classe média já estruturada justamente àquela que construiu as Expressões de Poder citadas anteriormente.

O Brasil ensaia uma ditadura técnico-financeiro-econômica.

\section{ANEXO 1}

\section{JUIZZO DE VALOR}

\section{O VALOR}

$\mathrm{Na}$ linguagem corrente idiomática encontrada na apreciação de fatos, acontecimentos, situações e condições, utilizam com freqüência o «juizo de valor». Corresponde isso a um julgamento e a uma decisão baseados na ciência, na prática e na experimentação. As três categorias se juntam para convergirem a um ponto onde o pensamento consegue a síntese de convicção. A expressão surgiu da teologia parecendo ter sido empregada primitivamente por Ritdchl em sua obra ( Die christliche Lehre von der Rechtfertigung und Versöhnung», 1870 1874). Nasceu da discussão sôbre 
julgamentos metafísicos e julgamentos religiosos diante da relação entre existência e valor. A expressão «juizo de valor», em que pêse à contribuição positiva e de verdade científica do mo mento, nunca pode afastar - se da relatividade do valor. $O$ valor, tal como o poder, se refere a um pensamento de comparação ou de ação para, por ou contra alguma coisa. Assim, pois, ainda mais se aprofunda a relatividade e personalismo com que se impóe o «juizo de valor». Evidentemente, o têrmo valor dentro da rela tividade contém formas concretas, mas positivamente incidenciais. Assim a indeterminação «ter valor» não é geralmente o mesmo que «ter um valor». A idéia de valor ocorre em larga faixa de inter pretação; no sentido subjetivo, nos inclinamos para o «ter um valor» e no objetivo «ser um valor». Nesta última, pode-se sentir uma significação de «um todo e permanente» e no outro, parcial e distinto. $O$ que perdura imutável é a relatividade e a utilidade configurada pela comparação: a ação para, por ou contra alguma coisa. No deserto, o dinheiro pode não representar qualquer valor diante do "valor da água», diante da sêde intensa. Maior «valor» demonstra aquêle que socorre sem exigir a troca da água pelo dinheiro. Tal ato atesta um caso humano de «ter valor moral», de natureza e categoria permanentes e totais contra o «ser valor» cuja relatividade leva a nenhum valor em condições diferentes. Naquela categoria, deveríamos sustentar o «juizo de valor», ro que respeita a tradições históricas, objetos de uso de personalidades nacionais e da Humanidade, as lembranças sentimentais e o cultivo dos exemplos morais do passado. Lembramos aqui a carta de Descartes a Princesa Elizabeth (Tratado das Paixões, T. IV, 284) : «O valor das coisas não é um fato». Já Paul Janet ( $\mathrm{A}$ Moral, 1874,152 ) ainda mais se estendia dizendo «As coisas diferem excelência». Para Mentré, não existe valor estritamente individual; os julgamentos de valor são coletivos. Realmente, qualquer idéia de valor tem que representar uma ação social qualquer que seja o significado intrínseco de sua possibilidade. É o estigma firmado da relatividade de conceituação. Durkheim analisou sob outros as pectos quando escreveu «julgamentos de valor e julgamentos de realidade», na Revista de Metafísica (julho, 1911, 451). Separa, vidade dos valôres «julgáveis» científica e matemática da subjetique mais possam afetar a conduta de julg sujeição às impressões senta a sua facêta mais ou menos de julgamento. Cada qual aprea decisão de seu julgamento. vemos a grande faixa de interpretaç̃ da verdade, por exemplo, de probabilidade, que muitas vêzes ãa, compreendendo os graus ciência, os têrmos extremos vẽzes nos surpreende. Mesmo na tempo, sendo, pois, uma verdade sempreficação ao correr do 
exato de valor é difícil de ser precisado. A variação entre fato e direito, de desejável, da necessidade e do desinterêsse, dos momentos irregulares, das sensações vegetativas que dinamizam a númena mente humana e dos reflexos decorrentes das manifestações sensoriais, incorrem na apreciação de um valor considerado.

\section{O JULGAMENTO}

A decisão mental nos leva a um caminho decorrente de conhecimentos científicos, de uma síntese lógica, de uma crítica, de uma capacidade de normas assimiladas, de uma inteligência cultivada, de uma cultura sedimentada e de uma disposição psicológica envolvida em um turbilhão de reflexos condicionados da biologia, da vida de relações sentimentais e sociais, e da ação mesma, profissional.

O julgamento pode não ser considerado um ato e sim uma «faculdade». Leva à faculdade de «pensar» no particular de um conteúdo universal, em uma determinação ou reflexão, como bem assinalou Barni ao criticar a «Crítica de Julgamento» de Kant (1846) .

$\mathrm{Na}$ decisão provocada pelos conhecimentos científicos, impera a ordem normativa de uma situação opinativa «predominante» no momento, podendo mesmo ser motivo de uma influência de grupos, escolas e «outros interêsses». As provas aceitas para o julgamento em uma decisão de verdade científica também estão sujeitas a todos os percalços que envolvem a decisão. Ela é uma outra decisão anterior a comandar um julgamento posterior. Os fatos precisam ser julgados em cadeia, sendo cada qual objeto de decisão. Do particular passa ao universal. A questão é extremamente complexa e movediça.

O julgamento lógico estabelece pontos de reparo, um jôgo de relações e condicionamentos no sentido mais geral, seja a título de verdade firme ou provisória, fictícia ou real, digressão por áreas hipotéticas, etc. Uma prece, por exemplo, não constitui pròpriamente um julgamento, porque ela não é nem verdadeira nem falsa. Nestas idéias, Aristóteles sentiu, na sua filosofia sensorial, a necessidade de decisão, visando o processo de satisfação constante, progressiva e interminável do gênero humano. Assim, êle considera o têrmo de apêlo ao «sujeito» e outro, mais complexo, em que se afirma e se nega, ao apelar-se para o «predicado». Nas «Primeiras Análicon" a sü divisão persiste quando considera um julgamento analitico, sintético ou isolado, etc. Considera o de inclusão de preatcação, de inerência e de relação, etc. Na primeira, distingue a relação entre duas classes entre Gênero e Espécie. Na predicação, que é ação de afirmar ou negar um predicado tomado no sentido de norma geral, mantendo a relação e a vinculação subjetiva: «os 
caracteres dependem dos temperamentos». É um julgamento de predicação no contexto de uma condição e de uma relação. $\mathrm{Na}$ inerência, subentenderse uma determinação e uma essencialidade. Assim, é a «fraqueza inerente à natureza humana». Compreenderse, pois, uma «maneira de ser» mais ou menos estabelecida integrada em uma «verdade atual firme». O julgamento de relação precisa ser isento da idéia de tomar relativo, seja para subjetivo, ou imperfeito e mediocre. A relação e o caráter de dois ou vários objetos de pensamento concebidos como tendo ou podendo ser compreendidos em uma ação intelectual única, de natureza determinada. Em um conjunto, pois, poderemos considerar a identidade, a coexistência, a sucessão, a correspondência, a causalidade, a filiação etc. (Lalande). A relação importa analogia, condicionamento mútuo, comparação, transformação pela ação dos fatôres de relação, reformulação de um conjunto na observação global do atingir um processo mais ou menos sensível de modificações e transformações. Seguem $\sim$ se, assim, as proposições atributivas, de inerência, predicativas, etc. $\mathrm{Na}$ categoria de relação, o silogismo gradativas até chegar à conclusã̃o onde se estabelecem as premissas sua vez ao mesmo processo, somando Cada conclusão se submete por total passivel de formar um juizo conjunto.

\section{O JUIZO DE VALOR}

A decomposição dos dois fatôres e agora a sua junção em uma semântica compreensível nos induz a profundidade do Relativo. Esse vocábulo se opõe ao Absoluto, mas não em todós os do Relativo. A posição relôbre o Infinito cabem tôdas elas dentro e dois corpos, não se refere entre duas doutrinas, duas coisas Absoluto. A conclusão acêre a qualquer pensamento acêrca do leira, partida de um Estadista da situação histórico-social braside valor», daria a mim oportunidare o qual eu fizesse um «juizo «juizo de valor». Mas como sandade de fazer sôbre o assunto um homens de govêrno, eu fico sem Brasil de hoje só encontramos «juizo de valor», na fase histórica possibilidade de fazer aquêle social, especialmente politica, nosso de seu processo de evolução Estadista e êle se recolheu ou país «esvaziou» o campo do político que ultrapassou tôdas as sensareceu. O Estadista é o de personalismo, especificamente, sensações de individualismo e Não se altera mesmo que possa pelos sua própria personalidade. tos ser julgado como traidor à pes seus atos, idéias e pensamenmano, venal, ignorante, sábio, etc. Fira, covarde, desonesto, desusamento humano pela Pátria e pela-se na realidade de um pen- 
elogios, apoios e oposições, julgando as ações que lhe sejam favoráveis apenas como coincidência de valôres semelhantes aos seus. Nenhuma manifestação, contudo, é capaz de demonstrar que resulte em uma vantagem individual para qualquer um. Não serve ao individualismo nem ao personalismo. Serve, sim, ao ideal da coletividade por êle conceituada. Nunca pretende ser um grande homem na conceituação corrente de virtudes morais, competência, dignidade, etc. Não se detém por demais com a conjuntura, tendo a visão projetada na estrutura e no futuro. Exatamente ao contrário dos espíritos primários, provincianos, individualistas e personalistas. O Estadista não vive a sua Época, mas pensa, age e se integra nela; como se esperasse viver e colhêr os louros das benesses do futuro por êle construídas. A Moral dos Estadistas é diferente da moral dos demais cidadãos.

\section{Terminamos assitn com um «juizo de valor»}

\section{ANEXO 2}

\section{OPINLÃO PÚBLICA}

\section{DEFINIÇÕES}

\section{«Nada existe de absolutamente certo ou errado acêrca de cada definição». - MAED STONE.}

Definição - «Constitui o estrato de uma filosofia que, espelhando o pensamento do definidor, obriga a um esfôrço mental para compreendê-lo». J. Almeida Rios.

Opinião do Povo - «Atitude consciente e decisiva de certeza sôbre fatos, situações e condições de uma população, difícil de ser alterada ou modificada» - J. Almeida Rios.

Opinião Pública - «Inclinação para a verdade de um fato sem possuir, contudo, os elementos objetivos e subjetivos de certeza. Imprevistos, fatos emocionais, ocorrências sentimentais podem mudar ràpidamente a interativa até então seguida». - J. Almeida Rios.

Povo - «Sociedade composta de um número variável de grupos locais, de relativa homogeneidade cultural, ocupando um território definido, com consciência de semelhança. Um povo pode compreender grupòs racialmente diversos».

Massa - «Agregação social que se constitui influenciada por interêsse qualquer, caracterizada por baixo grau de coesão e de organização; é formada de elementos oriundos de diversas camadas sociais, permanecem anônimos e fisicamente separados».

Multidão - «Qualidade mental e psíquica inorgânica, instintiva e desordenada de um grupo social ou aglomerado heterogêneo, agindo pelas impressões subconscientes, podendo ir até à autodestruição».

Lider - «Elemento social definidor e eficaz, transmissor de idéias e sentimentos sincrônicos como aquêles de um grupo social, quaisquer que sejam os fatos históricos e emocionais provocantes. Um lider existe nêle mesmo como qualidade orgânica». 

Atitude - «Predisposição consciente para um juizo, uma opinião e uma
ação». - J. Almeida Rios.

Empatia - «Tendência para sentir o que se sentiria se se estivesse na situação de outra pessoa». A capacidade ou dom empático é uma vocação interêsses tidos ou que precisam com sucesso a interpretação de aspirações e

Método - odmitidos como comuns.

dałmente uma série de operações a como um programa que regula antecipacom o fim de atingir a determinado resultad e assinala certos erros a evitar,

Idéi - Lalande.

Idéia - «Um produto do pensamento». - J. Almeida Rios.

Ideal - «Uma realização inacabada do pensamento». - J. Almeida Rios. Ideologia - 《Disciplina do produto do pensamento solicitando uma dou-
trina». J. Almeida Rios.

Opinião Pública - (Técnica) - «Maneira de pensar, de sentir, de manifestar-se e de agir de um grupo social, podendo ser modificada, ampliada, distorcida, encaminhada, reformada e reformulada». - Willialm Lambert.

Emoção - «Emoção ê qualquer choque sofrido no senso afetivo, podendo repercutir nas áreas psicomotoras e neurovegetativas. Sensações de prazer, dor,
mêdo ou surprêsa podem provocá-la». - J. Almeida Rios.

Público - «E' qualquer coleção de pessoas que um determinado objetivo ou situação associa, independente de circunstâncias, de espaço e de tempo».
- Aldo Xavier da Silva.

Iuizo de Valor - «Decorrência de uma sintese de informações sôbre a qual se firma um julgamento tido como verdadeiro e a que se dá o valor por, para ou contra em relação a algumma coisa». - J. Almeida Rios.

PROPAGANDA - Definição e conceito:

Propaganda - E' um método de aplicação dos diferentes meios de comunicações humanas visando atingir fins e perseguir objetivos preestabelecidos».
- J. Almeida Rios.

Uma propaganda exige:

Ulma Análise - Pesquisa, estudo e concepção do meio,

Ulma tese - Pesquisa, estudo, critica e conclusões sôbre as resistências da atitude e da opinião e das possibilidades. Utma sintese - Pesquisa, estudo e crítica sôbre a decisão com a mudança
de atitude e de opinião.

Indice Cumulativo - Estabilização das finalidades a vegetativo dêste resultado com firmeza da nova atitudes atingidas e progresso e opinião. 